\title{
Produção do capim Piatã submetido a diferentes fontes de fósforo
}

\author{
Daniel G. Dias ${ }^{1}$, Rodinei F. Pegoraro ${ }^{2}$, Dorismar D. Alves ${ }^{3}$, \\ Edson M. V. Porto ${ }^{4}$, José A. dos Santos Neto ${ }^{5} \&$ Ignacio Aspiazú $^{6}$
}

\section{Palavras-chave: rendimento \\ Urochloa brizantha \\ matéria seca \\ adubação fosfatada}

\begin{abstract}
R E S U M O
O fósforo é primordial para as plantas forrageiras e a adubação combinada com fontes fosfatadas reativas e naturais podem aumentar a qualidade e a produção do capim Piatã. Objetivou-se avaliar a produção e a relação entre os componentes do capim Piatã submetido a diferentes combinações de fosfato reativo e natural. $\mathrm{O}$ experimento foi conduzido em casa de vegetação sob blocos casualizados, com sete repetições. Os tratamentos consistiram de quatro combinações de fontes de fosfato reativo e natural (equivalente a $70 \mathrm{~kg} \mathrm{ha}^{-1} \mathrm{de}$ $\mathrm{P}_{2} \mathrm{O}_{5}$ ): ausência de adubação fosfatada (controle); adubação com fosfato natural reativo Argélia; adubação com 50\% de fosfato natural reativo Argélia e 50\% de superfosfato simples e adubação com superfosfato simples. O capim Piatã foi cultivado durante três cortes para caracterização da produção de matéria seca de perfilhos, folhas, pseudocolmo, raízes e relações entre folha/pseudocolmo e parte aérea/raiz. A adubação fosfatada, independentemente da fonte, propiciou incremento na produção da matéria seca das folhas, pseudocolmo e da parte aérea do capim Piatã nos segundo e terceiro cortes avaliativos e na média dos cortes, indicando aumento da produção de forragem.
\end{abstract}

\section{Key words:}

yield

Urochloa brizantha

dry matter

fertilizer phosphorus

\section{Production of Piata grass under different phosphorus sources}

\begin{abstract}
A B S T R A C T
Phosphorus is essential for forage crops and fertilization combined with reactive and natural sources of phosphorus can increase the quality and yield of Piata grass. The objective of this study was to evaluate the production and the relationship between the components of Piata grass subjected to different combinations of reactive and rock phosphate. The experiment was conducted in a greenhouse in a randomized block design with seven replications. Treatments consisted of four combinations of sources and reactive phosphate rock (equivalent to $70 \mathrm{~kg} \mathrm{ha}^{-1}$ of $\mathrm{P}_{2} \mathrm{O}_{5}$ ): absence of phosphate fertilizer (control); fertilization with Algerian reactive rock phosphate; fertilization with $50 \%$ of Algerian reactive rock phosphate and $50 \%$ fertilization with single superphosphate and single superphosphate fertilization. The Piata grass was grown for three cuttings for characterization of dry matter production of tillers, leaves, pseudostem, relations between roots and leaf/pseudostem and shoot/root part. Phosphorus fertilization, regardless of the source, provided an increment in the production of dry matter of leaves, pseudostem and shoots of Piata grass in the second and third cuttings of evaluation and on the average, indicating increase in forage production.
\end{abstract}

Protocolo 081-2014 - 13/03/2014 • Aprovado em 05/12/2014 • Publicado em 02/03/2015

${ }^{1}$ UNIMONTES. Janaúba, MG. E-mail: danielgon_d@hotmail.com (Autor correspondente)

${ }^{2}$ DCA/UNIMONTES. Janaúba, MG. E-mail: rodinei_pegoraro@yahoo.com.br

${ }^{3}$ DCA/UNIMONTES. Janaúba, MG. E-mail: dorismardavid@hotmail.com

${ }^{4}$ DCA/UNIMONTES. Janaúba, MG. E-mail: edsonporto9@yahoo.com.br

${ }^{5}$ DCA/UNIMONTES. Janaúba, MG. E-mail: jose.neto@unimontes.br

${ }^{6}$ DCA/UNIMONTES. Janaúba, MG. E-mail: aspiazu@gmail.com 


\section{INTRODUÇÃo}

As gramíneas forrageiras são a principal fonte de alimentos para os bovinos de vez que, no Brasil, os animais são criados, em sua maioria, em sistema extensivo, em pelo menos uma das fases de crescimento. A forrageira Urochloa brizantha (Syn. Brachiaria brizantha) cv. Piatã vem ganhando espaço nas áreas destinadas ao cultivo de pastagens por ser considerada produtiva, apresentar maior acúmulo de folhas, maior tolerância a solos com má drenagem (Pimenta, 2009) e apresentar boa aceitação pelos animais, dentre as diversas espécies do gênero (Valle et al., 2007). No entanto, em sistemas mais produtivos alguns fatores de produção, como a nutrição fosfatada equilibrada para a forrageira, ainda podem ser considerados indefinidos.

Doses equilibradas e fontes adequadas de fósforo implicam em maior produção e qualidade de forrageiras (Bonfim-Silva \& Monteiro, 2006), uma vez que o fósforo é um nutriente crucial no metabolismo das plantas na transferência de energia da célula, respiração e fotossíntese, sendo componente estrutural de macromoléculas, genes e cromossomos e integrantes de diversas moléculas químicas, como açúcares fosfatados, nucleotídios, assim como de muitas coenzimas, fosfoproteínas e fosfolipídeos, ácido fítico, além de ser parte estrutural do difosfato de adenosina (ADP) e do trifosfato de adenosina (ATP), participando de um grande número de compostos essenciais de vias metabólicas e nos processos de transferência de energia sendo ainda essencial para a divisão celular, devido ao seu papel na estrutura dos ácidos nucleicos (Taiz \& Zeiger, 2009).

Dentre os nutrientes que mais limitam a produção das forrageiras, o P merece destaque em virtude da baixa disponibilidade deste nutriente nos solos brasileiros, limitando a produção de forragens uma vez que a utilização de adubo fosfatado aumenta significativamente a produção das gramíneas (Lima et al., 2007) e do importante papel que desempenha nas plantas, influenciando no desenvolvimento do sistema radicular e do perfilhamento das gramíneas, visto que este elemento exerce grande influência sobre o número e o peso de perfilhos, por serem fundamentais à maior produtividade $\mathrm{e}$ persistência das forrageiras e à produção de massa seca; assim, sua deficiência limita a capacidade de produção das pastagens (Cecato et al., 2008).

A interação específica do fósforo com os solos de clima tropical e sua importância no aumento da produção de forrageiras, condicionam a necessidade do uso eficiente de P para uma produção satisfatória e sustentável (Araújo et al., 2005). A utilização de fontes de $\mathrm{P}$ de alta solubilidade (fosfatos reativos) vinculadas a fosfatos de baixa solubilidade (fosfatos naturais) pode equilibrar a nutrição fosfatada em forrageiras perenes aumentado a qualidade e a produção de forrageiras (Soares et al., 2007) reduzindo o custo monetário de produção.
Tendo em vista que a adubação fosfatada adequada proporciona aumento na produção e o desenvolvimento das gramíneas objetivou-se, com este estudo, determinar a produção e a relação entre os componentes do capim Piatã submetido a diferentes combinações de fosfato reativo e natural.

\section{Material e Métodos}

O estudo foi conduzido em casa de vegetação, na região norte do Estado de Minas Gerais, localizada a $516 \mathrm{~m}$ de altitude, com coordenadas de $15^{\circ} 47^{\prime} 18^{\prime \prime}$ de latitude Sul e $43^{\circ} 18^{\prime} 18^{\prime \prime}$ de latitude Oeste. O clima da região, segundo a classificação de Köppen, é do tipo BSwh (clima quente de caatinga), com chuvas de verão e períodos secos bem definidos no inverno, com precipitação pluviométrica média de 750 a $1.250 \mathrm{~mm} \mathrm{ano}^{-1}$, distribuída irregularmente no período chuvoso de outubro a março, temperatura média anual de $24^{\circ} \mathrm{C}$, insolação de $2.700 \mathrm{~h}$ anuais, umidade relativa média de $65 \%$. Foi adotado o delineamento em blocos casualizados com sete repetições constatando-se quatro tratamentos, totalizando 28 unidades experimentais.

Os tratamentos estudados no cultivo do capim Piatã foram: ausência de adubação fosfatada (controle); fosfato natural reativo Argélia (FN) com $28 \%$ de $\mathrm{P}_{2} \mathrm{O}_{5}$ total, $0,11 \%$ de $\mathrm{K}_{2} \mathrm{O}$ e $30 \%$ de $\mathrm{Ca}$; fosfato natural reativo Argélia e superfosfato simples $(\mathrm{FN}+\mathrm{SS})$, sendo a dose equivalente a $50 \%$ na fonte solúvel e $50 \%$ no fosfato natural; superfosfato simples (SS) com $17 \%$ de $\mathrm{P}_{2} \mathrm{O}_{5}$ total, $16,08 \%$ de Ca e $11 \%$ de $\mathrm{S}$. A dose de fósforo recomendada para os tratamentos equivaleu a $70 \mathrm{~kg} \mathrm{ha}^{-1} \mathrm{de}$ $\mathrm{P}_{2} \mathrm{O}_{5}$, de acordo com a recomendação para o uso de corretivos e fertilizantes em Minas Gerais (Cantarutti et al., 1999).

As unidades experimentais utilizadas foram compostas por vasos plásticos com capacidade de $5 \mathrm{dm}^{3}$ de solo, que foram preenchidos com Latossolo Vermelho eutrófico coletado na camada de 0 a $20 \mathrm{~cm}$ de profundidade (Tabela 1 ). O solo coletado passou pelo processo de secagem à sombra, destorroamento e peneiramento em malha de $6 \mathrm{~mm}$ para acondicionamento nos vasos plásticos de $5 \mathrm{~L}$. A adubação fosfatada foi aplicada de modo localizado a aproximadamente 5 $\mathrm{cm}$ de profundidade e logo abaixo das sementes da forrageira.

A semeadura foi realizada em 21 de novembro de 2011 com aproximadamente 30 sementes do capim Piatã, na profundidade de um centímetro abaixo da superfície do solo, na mesma ocasião da adubação fosfatada. Aos 15 dias após a semeadura foi realizado o primeiro desbaste eliminandose $50 \%$ das plantas presentes no vaso; aos 21 dias após a semeadura foi realizado o segundo desbaste no final do qual permaneceram apenas sete plantas por vaso e os parâmetros utilizados para seleção das plantas que permaneceram nos vasos foram homogeneidade e posição dentro do vaso e tamanho; enfim, aos 52 dias após a semeadura foi realizado o corte de uniformização a $10 \mathrm{~cm}$ de altura do solo.

Tabela 1. Composição química da amostra do Latossolo Vermelho eutrófico, coletado no município de Janaúba Minas Gerais

\begin{tabular}{|c|c|c|c|c|c|c|c|c|c|c|c|c|c|}
\hline \multirow{2}{*}{$\mathrm{pH}^{1}$} & \multirow{2}{*}{$\begin{array}{c}\mathrm{MO}^{2} \\
\text { dag } \mathrm{kg}^{-1}\end{array}$} & $\mathrm{P}^{3}$ & $\mathrm{~K}^{3}$ & $\mathrm{Ca}^{4}$ & $\mathrm{Mg}^{4}$ & $\mathrm{Al}^{4}$ & $\mathbf{H}+\mathbf{A l}^{5}$ & SB & $t$ & $T$ & V & $\mathbf{m}$ & Prem $^{6}$ \\
\hline & & \multicolumn{2}{|c|}{$\mathrm{mg} \mathrm{dm}^{-3}$} & \multicolumn{7}{|c|}{$\mathrm{cmol}_{\mathrm{c}} \mathrm{dm}^{-3}$} & \multicolumn{2}{|c|}{$\%$} & $\mathrm{mg} \mathrm{L}^{-1}$ \\
\hline 5,0 & 0,9 & 3,3 & 72,0 & 2,2 & 1,1 & 0,1 & 2,3 & 3,6 & 3,7 & 5,9 & 61 & 3 & 36,5 \\
\hline
\end{tabular}

${ }^{1} \mathrm{pH}$ em água; ${ }^{2}$ Colorimetria; ${ }^{3}$ Extrator: Mehlich-1; ${ }^{4}$ Extrator: $\mathrm{KCl} 1 \mathrm{~mol} \mathrm{L-1} ;{ }^{5} \mathrm{pH}$ SMP; ${ }^{6}$ Solução equilíbrio de P 
Durante o período de cultivo do estudo foi realizada adubação nitrogenada, segundo Cantarutti et al. (1999) e efetuada adubação equivalente a $200 \mathrm{~kg} \mathrm{ha}^{-1}$ de $\mathrm{N}$, parcelada em quatro vezes sendo a primeira adubação realizada após germinação com aplicação de $0,28 \mathrm{~g}$ de ureia ( $44 \%$ de N) por vaso. As outras três adubações foram realizadas após o corte de uniformização e após os primeiro e segundo cortes avaliativos.

A adubação com sulfato de potássio $(0,6 \mathrm{~g}$ por vaso de $\mathrm{K}_{2} \mathrm{SO}_{4}$ ) foi realizada no tratamento controle e no $\mathrm{FN}$, para balancear o enxofre presente no superfosfato simples aplicado no tratamento SS. Da mesma forma foi efetuada adubação com cloreto de potássio $(0,57 \mathrm{~g}$ por vaso de $\mathrm{KCl})$ nos tratamentos controle e no SS, para balancear a adubação de potássio presente no fosfato natural reativo Argélia adicionada ao tratamento FN.

A determinação da altura média das plantas nos vasos foi realizada antes de cada corte avaliativo com intervalo de 30 dias contados a partir do corte de uniformização, juntamente com a contagem de perfilhos por vaso; posteriormente foi realizado o primeiro dos três cortes avaliativos todos com o mesmo intervalo e a $10 \mathrm{~cm}$ de altura do solo.

O material vegetal resultante dos cortes avaliativos foi separado em folhas e pseudocolmo e as frações coletadas de cada corte do experimento foram levadas para estufa de circulação de ar forçada a $65^{\circ} \mathrm{C}$ por $72 \mathrm{~h}$, para determinação da matéria seca tendo-se determinado o acumulado total dos três cortes avaliativos, com os valores obtidos na produção da matéria seca da folha e do pseudocolmo.

Após a realização do último corte foi realizada a extração das raízes das plantas presentes nos vasos as quais foram lavadas em água corrente e peneiradas em peneira com malha de $2 \mathrm{~mm}$, para determinação da produção da matéria seca das raízes.

Com os valores médios obtidos nos paramentos avaliados foram determinados o peso médio do perfilho, a relação folha/ pseudocolmo e a relação parte aérea/raiz.

As características avaliadas foram submetidas à análise de variância e as médias de tratamento foram comparadas pelo teste Scott-Knott a 0,05 de significância para comparação das médias, por meio do programa de análises estatísticas e planejamento de experimentos - SISVAR (Ferreira, 2008).

\section{Resultados e Discussão}

No segundo e no terceiro cortes avaliativos e no acumulado dos três cortes, a adubação fosfatada incrementou a produção de matéria seca de todos os componentes da planta e da parte aérea em comparação ao tratamento controle; entretanto não se obteve diferença significativa $(\mathrm{p}>0,05)$ entre as combinações de SS e FN para essas características de produção (Tabela 2). No primeiro corte avaliativo a adubação fosfatada não interferiu na produção de matéria seca das folhas nem no pseudocolmo da parte área do capim Piatã.

A adubação com $70 \mathrm{~kg} \mathrm{ha}^{-1}$ de $\mathrm{P}_{2} \mathrm{O}_{5}$ na forma de SS e na média entre os três cortes avaliativos, incrementou em $29 \%$ a produção de matéria seca capim Piatã em comparação à ausência de adubação fosfatada (Tabela 2). Mesmo com potencial incremento da forrageira após a adubação com SS, pode-se indicar que o aumento relativo na produção de
Tabela 2. Produção de matéria seca das folhas, pseudocolmo e da parte área do capim Piatã em três cortes avaliativos e o acumulado dos três cortes avaliativos, em função de diferentes fontes de fósforo

\begin{tabular}{|c|c|c|c|c|c|}
\hline \multirow{2}{*}{ Cortes } & \multicolumn{4}{|c|}{ Tratamentos $^{(1)}$} & \multirow{2}{*}{$\begin{array}{l}\text { CV } \\
(\%)\end{array}$} \\
\hline & Controle & FN & $F N+S S$ & SS & \\
\hline \multicolumn{6}{|c|}{ Folha $\left(g\right.$ vaso-1 ${ }^{-1}$} \\
\hline $1^{0}$ & $4,82 \mathrm{a}$ & $5,68 \mathrm{a}$ & $5,98 \mathrm{a}$ & $6,06 \mathrm{a}$ & 17,72 \\
\hline $2^{0}$ & $4,97 \mathrm{~b}$ & $6,23 \mathrm{a}$ & $5,95 \mathrm{a}$ & $6,27 \mathrm{a}$ & 13,78 \\
\hline $3^{0}$ & $2,36 \mathrm{~b}$ & $3,84 \mathrm{a}$ & $3,91 \mathrm{a}$ & $4,54 \mathrm{a}$ & 18,21 \\
\hline Acumulado & $12,15 b$ & $15,75 \mathrm{a}$ & $15,84 \mathrm{a}$ & $16,87 \mathrm{a}$ & 10,65 \\
\hline \multicolumn{6}{|c|}{ Pseudocolmo (g vaso-1) } \\
\hline $1^{0}$ & $1,09 \mathrm{a}$ & $1,48 \mathrm{a}$ & $1,59 \mathrm{a}$ & $1,55 \mathrm{a}$ & 37,27 \\
\hline $2^{0}$ & $2,20 b$ & $2,90 \mathrm{a}$ & $2,97 \mathrm{a}$ & $2,91 \mathrm{a}$ & 12,45 \\
\hline $3^{0}$ & $0,33 \mathrm{~b}$ & $0,98 \mathrm{a}$ & $0,95 \mathrm{a}$ & $0,99 \mathrm{a}$ & 36,73 \\
\hline Acumulado & $3,62 b$ & $5,36 \mathrm{a}$ & $5,51 \mathrm{a}$ & $5,45 \mathrm{a}$ & 15,45 \\
\hline \multicolumn{6}{|c|}{ Parte aérea (g vasơ $\left.\sigma^{-1}\right)$} \\
\hline $1^{0}$ & $5,91 \mathrm{a}$ & $7,16 \mathrm{a}$ & $7,57 \mathrm{a}$ & $7,61 \mathrm{a}$ & 18,58 \\
\hline $2^{0}$ & $7,17 \mathrm{~b}$ & $9,13 \mathrm{a}$ & $8,92 \mathrm{a}$ & $9,18 \mathrm{a}$ & 11,78 \\
\hline $3^{0}$ & $2,69 \mathrm{~b}$ & $4,82 \mathrm{a}$ & $4,86 \mathrm{a}$ & $5,53 \mathrm{a}$ & 20,33 \\
\hline Aacumulado & $15,77 \mathrm{~b}$ & $21,11 \mathrm{a}$ & $21,35 \mathrm{a}$ & $22,32 \mathrm{a}$ & 10,55 \\
\hline
\end{tabular}

(1)Controle - Ausência de adubação fosfatada; FN - Fosfato natural reativo argélia; FN + SS - Fosfato natural reativo argélia + superfosfato simples; SS - Superfosfato simples; Médias seguidas de letras distintas na linha diferem entre si pelo teste de Scott-Knott a 0,05 de probabilidade

biomassa ficou abaixo do esperado. Possivelmente a rápida solubilidade do $\mathrm{P}$ presente no SS implicou na maior interação com os argilominerais de solos intemperizados, a médio período de cultivo, reduzindo a eficiência de absorção do $\mathrm{P}$ e a produção de capim Piatã. Segundo Ourives et al. (2010) quando se adiciona uma fonte solúvel de $\mathrm{P}$ em solos intemperizados, mais de $90 \%$ do total aplicado são adsorvidos na primeira hora de contato com o solo e Novais et al. (1980) também relatam que o maior tempo de contato solo-fosfato favorece sua maior solubilidade ocasionando menor disponibilidade de $P$ para as plantas.

No segundo corte o aumento médio de matéria seca obtido nos tratamentos com adubação em comparação com o controle foi de 19, 25 e $21 \%$ para os componentes da planta: folha, pseudocolmo e parte área, respectivamente mas no terceiro corte os incrementos corresponderam a 43, 66 e 47\%, nas folhas, no pseudocolmo e na parte área, respectivamente. Os resultados indicaram que as fontes de $\mathrm{P}$ foram eficientes no desenvolvimento do capim Piatã na fase de rebrotação, característica interessante tendo em vista a durabilidade da pastagem.

Costa et al. (2008) obtiveram, ao avaliar a resposta do capim Marandu a diferentes fontes de $\mathrm{P}$ em um Latossolo Vermelho distroférrico, efeito positivo da adubação fosfatada na produção total de forragem porém não encontraram diferença significativa entre as fontes de adubação fosfatada, superfosfato triplo (ST), fosfato reativo de Arade (FRA) e a mistura ST + FRA, exceção para o fosfato de Araxá (FA) em que a produção foi inferior às demais e Rezende et al. (2011) ressaltaram, avaliando a influência do $\mathrm{P}$ na $B$. brizantha $\mathrm{cv}$. Marandu, que houve uma estreita diferença na produção de matéria seca da parte aérea entre os tratamentos que receberam $100 \%$ de $\mathrm{P}_{2} \mathrm{O}_{5}$ aplicados no plantio; $75 \%$ de $\mathrm{P}_{2} \mathrm{O}_{5}$ aplicados no plantio e $25 \%$ de $\mathrm{P}_{2} \mathrm{O}_{5}$ em cobertura; $50 \%$ de $\mathrm{P}_{2} \mathrm{O}_{5}$ no plantio e $50 \%$ de $\mathrm{P}_{2} \mathrm{O}_{5}$ em cobertura; $25 \%$ de $\mathrm{P}_{2} \mathrm{O}_{5}$ no plantio e $75 \%$ de $\mathrm{P}_{2} \mathrm{O}_{5}$ em cobertura; $100 \%$ de $\mathrm{P}_{2} \mathrm{O}_{5}$ em cobertura. Segundo Malavolta (2006), o P promove maior crescimento da forrageira 
principalmente por desempenhar função estrutural na planta além de fazer parte de compostos orgânicos como o ATP, os aminoácidos e de todas as enzimas e assim participa de diversos processos metabólicos, em especial no processo de transferência e de armazenamento de energia.

No primeiro corte do capim Piatã verificou-se que o tratamento com as fontes combinadas (FN + SS) e o SS propiciou incremento na altura dos perfilhos em comparação com o controle e ao FN, obtendo-se 61,58 e 59,64 cm de altura, respectivamente (Tabela 3) indicando que a fonte de fosfato reativa (SS) possibilitou a maior absorção de P, incrementando a altura dos perfilhos. De acordo com Santos et al. (2002), a adubação fosfatada desempenha papel fundamental no perfilhamento das gramíneas e proporciona incremento na produtividade.

No segundo corte avaliativo a altura dos perfilhos no tratamento constituído de fosfato natural mais fosfato reativo foi superior $(\mathrm{p}<0,05)$ à dos demais tratamentos obtendo 71,67 $\mathrm{cm}$ (Tabela 3 ), seguido do tratamento com fosfato reativo $(68,17 \mathrm{~cm})$. Tal resultado pode estar vinculado ao efeito residual do fosfato natural reativo, maximizado na presença de fosfato reativo que, provavelmente, contribuiu para absorção suplementar do P pelo capim Piatã, considerada solubilizadora de fosfato natural na rizosfera contribuindo para obtenção de maior altura de plantas em comparação com a utilização de fontes isoladas de fosfato.

No terceiro corte avaliativo e na média dos três cortes (Tabela 3) obteve-se maior altura de perfilhos na presença da adubação fosfatada em comparação com o tratamento controle apresentando incremento médio na altura do perfilho de 10,63 e $8,04 \%$, respectivamente, no terceiro e na média dos cortes avaliativos. Os resultados encontrados no presente estudo corroboram com Oliveira et al. (2000) e Belarmino et al. (2003), que observaram incremento na altura dos perfilhos do capim Tanzânia em virtude da aplicação de P. Rezende et al. (2011) verificaram que não houve diferença $(\mathrm{p}>0,05)$ entre os tratamentos que receberam adubação fosfatada para altura do perfilho, obtendo uma altura média de $43,09 \mathrm{~cm}$.

Tabela 3. Altura, densidade e peso dos perfilhos do capim Piatã em três cortes avaliativos e a média dos três cortes avaliativos, em função de diferentes fontes de fósforo

\begin{tabular}{|c|c|c|c|c|c|}
\hline \multirow{2}{*}{ Cortes } & \multicolumn{4}{|c|}{ Tratamentos $^{(1)}$} & \multirow{2}{*}{$\begin{array}{l}\text { CV } \\
\text { (\%) }\end{array}$} \\
\hline & Controle & FN & $F N+S S$ & SS & \\
\hline \multicolumn{6}{|c|}{ Altura (cm) } \\
\hline $1^{0}$ & 54,57 b & $57,58 \mathrm{~b}$ & $61,58 \mathrm{a}$ & $59,64 a$ & 6,15 \\
\hline $2^{0}$ & $64,50 \mathrm{c}$ & $65,25 \mathrm{c}$ & 71,67 a & $68,17 \mathrm{~b}$ & 4,51 \\
\hline $3^{0}$ & $48,00 \mathrm{~b}$ & $54,83 a$ & $52,83 a$ & $53,47 a$ & 5,74 \\
\hline Média & $55,69 \mathrm{~b}$ & $59,22 \mathrm{a}$ & $62,03 \mathrm{a}$ & $60,43 \mathrm{a}$ & 3,61 \\
\hline \multicolumn{6}{|c|}{ Densidade } \\
\hline $1^{0}$ & $29,43 b$ & $34,33 a$ & $33,43 \mathrm{a}$ & $37,71 \mathrm{a}$ & 11,49 \\
\hline $2^{0}$ & $31,71 \mathrm{c}$ & $41,67 b$ & 38,57 b & $47,29 a$ & 14,49 \\
\hline $3^{0}$ & $41,71 b$ & $56,33 a$ & $53,57 \mathrm{a}$ & $60,29 a$ & 15,18 \\
\hline Média & $34,29 \mathrm{~b}$ & $44,11 \mathrm{a}$ & $41,86 \mathrm{a}$ & $48,43 \mathrm{a}$ & 12,01 \\
\hline \multicolumn{6}{|c|}{ Peso (g vaso-1) } \\
\hline $1^{0}$ & $0,04 \mathrm{a}$ & $0,05 \mathrm{a}$ & $0,05 \mathrm{a}$ & $0,04 a$ & 32,43 \\
\hline $2^{0}$ & $0,07 a$ & $0,07 \mathrm{a}$ & $0,08 \mathrm{a}$ & $0,06 \mathrm{a}$ & 15,60 \\
\hline $3^{0}$ & $0,01 \mathrm{~b}$ & $0,02 a$ & $0,02 \mathrm{a}$ & $0,02 a$ & 34,02 \\
\hline Acumulado & $0,10 a$ & $0,12 \mathrm{a}$ & $0,13 \mathrm{a}$ & $0,11 \mathrm{a}$ & 15,62 \\
\hline
\end{tabular}

${ }^{(1)}$ Controle - Ausência de adubação fosfatada; FN - Fosfato natural reativo argélia; FN + SS - Fosfato natural reativo argélia + superfosfato simples; SS - Superfosfato simples Médias seguidas de letras distintas na linha diferem entre si pelo teste de Scott-Knott a 0,05 de probabilidade
No primeiro, no terceiro e na média dos três cortes avaliativos, a densidade de perfilhos foi maior nos tratamentos que receberam adubação fosfatada em comparação ao tratamento controle (Tabela 3 ) tendo um ganho na população de perfilhos de 16, 27 e 24\%, respectivamente. Indicando que a adubação fosfatada proporciona grande influência no estabelecimento das pastagens sendo sua aplicação responsável por $80 \%$ do perfilhamento de espécies forrageiras (Mesquita et al., 2010).

A adubação com SS propiciou, no segundo corte avaliativo, maior densidade de perfilhos $(47,29)$ em comparação aos demais tratamentos (Tabela 3), possivelmente por atribuir intensa atividade meristemática em virtude do desenvolvimento dos perfilhos indicando que a fonte SS foi mais eficiente na disponibilização de $\mathrm{P}$ para o capim Piatã na fase inicial da rebrota da pastagem resultado este que já esperado pelo fato do SS ser uma fonte prontamente disponível. Foloni et al. (2008) corroboram a afirmativa de que as fontes à base de superfosfatos apresentam solubilidade relativamente elevada em água, razão pela qual deve obter alta eficiência agronômica a curto prazo.

A adubação com FN propiciou a obtenção de altura e densidade dos perfilhos intermediários àqueles dos demais tratamentos, indicando uma disponibilização gradual de $\mathrm{P}$, característica interessante ao cultivo de pastagem perene haja vista que a necessidade de reposição nutricional fosfatada deve ser constante durante o seu ciclo de cultivo. Segundo Caione et al. (2011), fertilizantes fosfatados de baixa solubilidade em água e que tenham boa solubilidade em ácidos fracos, como o ácido cítrico e citrato neutro de amônio, liberam o $\mathrm{P}$ no solo mais lentamente diminuindo sua fixação no solo, característica interessante para as gramíneas do gênero Brachiaria que possuem a capacidade de acidificação do solo proporcionando, então, a reatividade do FN, de acordo com o seu desenvolvimento. Neste sentido, Guedes et al. (2009) relatam que fontes de $\mathrm{P}$ de menor solubilidade apresentam menor eficiência do que os fosfatos solúveis em curto prazo porém em longo prazo seu efeito residual é geralmente maior.

Oliveira et al. (2012) também observaram, trabalhando com diferentes fontes de $\mathrm{P}$ avaliando a produtividade do capim Piatã e Mombaça, aos 15 dias após emergência (DAE), que os tratamentos estudados não alteraram a densidade dos perfilhos mas se verificou diferença significativa aos 30 DAE, sendo os tratamentos com SS e farinha de ossos os que apresentaram melhores resultados. Em relação ao número de perfilhos avaliados aos 60 DAE, observou-se que houve significância entre os tratamentos sendo que as parcelas com $\mathrm{P}$ apresentaram resultados superiores aos do controle.

Lima et al. (2007) não constataram, avaliando diferentes fontes e doses de P no estabelecimento do capim Marandu, diferenças significativas entre as fontes aos 30 dias após o plantio (DAP) e também não observaram diferenças entre os tratamentos com fosfatagem em relação ao controle não influenciando a densidade do perfilhamento do capim Marandu; aos $60 \mathrm{DAP}$ já observaram respostas em perfilhamento, para as diferentes fontes de $\mathrm{P}$.

No primeiro, no segundo e na média dos cortes avaliativos, verificou-se que os tratamentos constituídos de adubação fosfatada não proporcionaram acréscimo no peso dos perfilhos 
do capim Piatã; contudo, no terceiro corte avaliativo os tratamentos com a presença de $\mathrm{P}$ foram superiores $(\mathrm{p}<0,05)$ ao controle, proporcionando um incremento médio de $50 \%$ (Tabela 3). Tal resultado pode, porém, não estar relacionado com o efeito do P, sendo este associado ao efeito compensatório entre a densidade e o peso dos perfilhos existentes na comunidade vegetal, cujo aumento na população de perfilhos influenciará na redução do peso dos perfilhos, como pôde ser observado por Dias et al. (2012).

A relação folha/pseudocolmo do capim Piatã não foi influenciada pelas fontes FN nem FN na presença de SS e SS, não havendo diferença $(\mathrm{p}>0,05)$ entre os tratamentos em ambos os cortes, tal como na média dos cortes (Tabela 4); observou-se, no entanto, que as relações médias encontradas foram superiores à relação 1:1 considerada o limite crítico entre a relação existente entre qualidade e quantidade de forragem (Andrade et al., 2000). Segundo Euclides et al. (2000), esta relação guarda relação direta com o desempenho dos animais em pastejo; quando a relação lâmina foliar/pseudocolmo apresenta valores próximos ao nível crítico 1:1 a qualidade da forragem é prejudicada de vez que aumenta a porcentagem de fibra que, em contrapartida, interfere no valor nutritivo da forragem consumida pelo animal e, desta forma, no seu comportamento durante o pastejo.

As diferentes combinações de fosfato reativo e natural não proporcionaram aumento para a produção da matéria seca da raiz e na relação parte área/raiz não have diferença significativa ( $\mathrm{p}>0,05)$ entre os tratamentos FN, FN + SS e SS em relação ao controle (Tabela 4), indicando que a adubação fosfatada não interferiu na produção de raízes nem na relação de biomassa produzida entre a parte aérea da planta e as raízes; acreditase, porém, que o P disponibilizado pelas fontes fosfatadas foi destinado para a parte área. Mesquita et al. (2004) verificaram, avaliando as características agronômicas do capim Marandu em um ensaio com solos de características distintas e com diferentes doses de $\mathrm{P}$, que a aplicação de $\mathrm{P}$ favoreceu mais a produção da parte aérea do que a da raiz em todos os solos.

De acordo com os resultados obtidos neste estudo, a adubação com FN, SS e a combinação do $\mathrm{FN}+\mathrm{SS}$ proporcionou incremento na produção de matéria seca, altura, densidade e peso de perfilhos refletindo na possibilidade de aumento da eficiência da rebrota, maior persistência da gramínea e maior qualidade nutricional da forragem; neste sentido se indica a

Tabela 4. Relação folha/pseudocolmo em três cortes avaliativos e a média dos cortes avaliativos, produção da matéria seca da raiz e relação parte área/raiz do capim Piatã, em função de diferentes fontes de fósforo

\begin{tabular}{|c|c|c|c|c|c|}
\hline \multirow{2}{*}{ Cortes } & \multicolumn{4}{|c|}{ Tratamentos $^{(1)}$} & \multirow{2}{*}{$\begin{array}{l}\text { CV } \\
(\%)\end{array}$} \\
\hline & Controle & FN & $F N+S S$ & SS & \\
\hline \multicolumn{6}{|c|}{ Folha/pseudocolmo } \\
\hline $1^{0}$ & $4,97 \mathrm{a}$ & $4,02 \mathrm{a}$ & $3,77 \mathrm{a}$ & $4,75 \mathrm{a}$ & 34,29 \\
\hline $2^{0}$ & $2,29 \mathrm{a}$ & $2,23 \mathrm{a}$ & $2,06 \mathrm{a}$ & $2,21 \mathrm{a}$ & 15,91 \\
\hline $3^{0}$ & $9,55 \mathrm{a}$ & $4,40 \mathrm{a}$ & $4,53 a$ & $5,19 a$ & 70,55 \\
\hline Média & $3,41 \mathrm{a}$ & $3,01 \mathrm{a}$ & $2,90 \mathrm{a}$ & $3,20 \mathrm{a}$ & 14,70 \\
\hline Raiz (g vaso-1) & $8,60 a$ & $13,35 \mathrm{a}$ & $12,05 \mathrm{a}$ & $10,70 a$ & 26,87 \\
\hline Parte área/Raiz & $2,04 \mathrm{a}$ & $1,66 \mathrm{a}$ & $1,87 \mathrm{a}$ & $2,14 \mathrm{a}$ & 26,96 \\
\hline
\end{tabular}

utilização de fontes reativa e natural como alternativa para a adubação fosfatada no cultivo do capim Piatã.

\section{Conclusões}

1. As adubações com fosfato natural reativo argélia, fosfato natural reativo argélia + superfosfato simples e superfosfato simples, proporcionam incremento na produção da matéria seca das folhas, pseudocolmo e da parte aérea do capim Piatã, no segundo e no terceiro cortes avaliativos e na média dos cortes.

2. A utilização de superfosfato simples e de fosfato natural reativo argélia na presença de superfosfato simples proporcionou maior altura dos perfilhos. 3 .

A utilização de fontes isoladas de superfosfato simples e fosfato natural reativo argélia ou em conjunto, aumentou a densidade de perfilhos de modo similar, tanto no primeiro quanto no terceiro cortes.

4. No segundo corte o superfosfato simples proporciona maior número de perfilhos no capim Piatã. As relações folha/ peseudocolmo e parte área/raiz e a produção da matéria seca da raiz, não foram alteradas com a adição de fontes de fósforo.

\section{Agradecimentos}

Ao Conselho Nacional de Desenvolvimento Científico e Tecnológico (CNPq), à Coordenação de Aperfeiçoamento de Pessoal de Nível Superior (CAPES) e à Fundação de Amparo à Pesquisa do Estado de Minas Gerais (FAPEMIG) pela concessão de bolsas e apoio financeiro.

\section{Literatura Citada}

Andrade, A. C.; Fonseca, D. M. da; Gomide, J. A.; Alvarez V., V. H.; Martins, C. E.; Souza, D. P. H. de. Produtividade e valor nutritivo do capim-elefante cv. Napier sob doses crescentes de nitrogênio e potássio. Revista Brasileira de Zootecnia, v.29, p.1589-1595, 2000. http://dx.doi.org/10.1590/S1516-35982000000600001

Araújo, W. F.; Sampaio, R. A.; Medeiros, R. D. Resposta de cultivares de soja à adubação fosfatada. Revista Ciência Agronômica, v.36, p.129-134, 2005.

Belarmino, M. C. J.; Pinto, J. C.; Rocha, G. P.; Furtini Neto, A. E.; Morais, A. R. de. Altura de perfilho e rendimento de matéria seca de capim Tanzânia em função de diferentes doses de superfosfato simples e sulfato de amônio. Ciência e Agrotecnologia, v.27, p.879885, 2003. http://dx.doi.org/10.1590/S1413-70542003000400021

Bonfim-Silva, E. M.; Monteiro, F. A. Nitrogênio e enxofre em características produtivas do capim-braquiária proveniente de área de pastagem em degradação. Revista Brasileira de Zootecnia, v.35, p.1289-1297, 2006. http://dx.doi.org/10.1590/S151635982006000500006

Caione, G.; Lange, A.; Benett, C. G. S.; Fernandes, F. M. Fontes de fósforo para adubação de cana-de-açúcar forrageira no cerrado. Pesquisa Agropecuária Tropical. v.41, p.66-73, 2011. http://dx.doi. org/10.5216/pat.v41i1.8497

Cantarutti, R. B.; Martins, C. E.; Carvalho, M. M. de; Fonseca, D. M. da; Arruda, M. L.; Vilela, H.; Oliveira, F. T. T. de. Pastagens. In: Ribeiro, A. C.; Guimarães, P. T. G.; Alvarez V., V. H. Recomendação para o uso de corretivos e fertilizantes em Minas Gerais: $5^{\text {a }}$ aproximação. Viçosa: Comissão de Fertilidade do Solo de Minas Gerais, 1999. Cap.18.5, p.332-341. 
Cecato, U.; Skrobot, V. D.; Fakir, G. R.; Branco, A. F.; Galbeiro, S.; Gomes, J. A. N. Perfilhamento e características estruturais do Capim-Mombaça, adubado com fontes de fósforo, em pastejo. Acta Scientiarum Animal Science, v.30, p.1-7, 2008.

Costa, S. E. V. G. de A.; Furtini Neto, A. E.; Resende, A. V. de; Silva, T. O. da; Silva, T. R. da. Crescimento e nutrição da braquiária em função de fontes de fósforo. Ciência e Agrotecnologia, v.32, p.1419-1427, 2008. http://dx.doi.org/10.1590/S141370542008000500010

Dias, D. G.; Porto, E. M. V.; Alves, D. D.; Santos Neto, J. A. dos; Gomes, V. M.; Silva, M. F. da; Santos, S. A. dos; Carvalho, M. A. M. Rendimento forrageiro do capim marandu submetido a diferentes fontes de fósforo. Revista Acadêmica Ciências Agrárias Ambientais, v.10, p.345-350, 2012. http://dx.doi.org/10.7213/ academica.7740

Euclides, V. P. B.; Cardoso, E. G.; Macedo, M. C. M. Consumo voluntário de Brachiaria decumbens cv. Basilisk e Brachiaria brizantha cv. Marandu sob pastejo. Revista Brasileira de Zootecnia, v.29, p.2200-2208, 2000.

Ferreira, D. F. SISVAR: Um programa para análises e ensino de estatística. Revista Symposium, v.6, p.36-41, 2008.

Foloni, J. S. S.; Tiritan, C. S.; Calonego, J. C.; Alves Júnior, J. Aplicação de fosfato natural e reciclagem de fósforo por milheto, braquiária, milho e soja. Revista Brasileira de Ciência do Solo, v.32, p.11471155, 2008. http://dx.doi.org/10.1590/S0100-06832008000300023

Guedes, E. M. S.; Fernandes, A. R.; Lima, E. do V.; Gama, M. A. P.; Silva, A. L. P. da. Fosfato natural de Arad e calagem e o crescimento de Brachiaria brizanta em Latossolo Amarelo sob pastagem degradada na Amazônia. Revista Ciências Agrárias, v.52, p.117-129, 2009.

Lima, S. de O.; Fidelis, R. R.; Costa, S. J. Avaliação de fontes e doses de fósforo no estabelecimento de Brachiaria brizantha cv. Marandu no sul do Tocantins. Pesquisa Agropecuária Tropical, v.37, p.100105, 2007.

Malavolta, E. Manual de nutrição mineral de plantas. São Paulo: Agronômica Ceres, 2006. 638p.

Mesquita, E. E.; Neres, M. A.; Oliveira, P. S. R. de; Mesquita, L. P.; Schneider, F.; Teodoro Júnior, J. R. Teores críticos de fósforo no solo e características morfogênicas de Panicum maximum cultivares Mombaça e Tanzânia-1 e Brachiaria híbrida Mulato sob aplicação de fósforo. Revista Brasileira de Saúde e Produção Animal, v.11, p.292-302, 2010.
Mesquita, E. E.; Pinto, J. C.; Furtini Neto, A. E.; Santos, I. P. A. dos; Tavares, V. B. Teores críticos de fósforo em três solos para o estabelecimento de capim-Mombaça, capim-Marandu e capim-Andropogon em vasos. Revista Brasileira de Zootecnia, v.33, p.290-301, 2004. http://dx.doi.org/10.1590/S151635982004000200004

Novais, R. F. de; Braga, J. M.; Martins Filho, C. A. Efeito do tempo de incubação do fosfato de Araxá em solos sobre o fósforo disponível. Revista Brasileira de Ciência do Solo, v.4, p.153-155, 1980.

Oliveira, I. P. de; Castro, F. G. F.; Moreira, F. P.; Paixão, V. V. da; Custódio, D. P.; Santos, R. S. M. dos; Faria, C. D.; Costa, K. A. de P. Efeitos qualitativo e quantitativo da aplicação de fósforo no capim Tanzânia. Pesquisa Agropecuária Tropical, v.30, p.37-41, 2000.

Oliveira, S. B.; Caione, G.; Camargo, M. F. Natali, A.; Oliveira, B.; Santana, L. Fontes de fósforo no estabelecimento e produtividade de forrageiras na região de Alta Floresta - MT. Global Science and Technology, v.5, p.1-10, 2012.

Ourives, O. E. A.; Souza, G. M.; Tiritan, C. S.; Santos, D. H. Fertilizante orgânico como fonte de fósforo no cultivo inicial de Brachiaria brizantha cv. Marandú. Pesquisa Agropecuária Tropical, v.40, p.126-132, 2010.

Pimenta, L. Capim novo a caminho. Revista ABCZ, v.50, p.18-20, 2009.

Rezende, A. V. de; Lima, J. F. de; Rabelo, C. H. S.; Rabelo, F. H. S.; Nogueira, D. A.; Carvalho, M.; Faria Júnior, D. C. N. A. de; Barbosa, L. de A. Características morfofisiológicas da Brachiaria brizantha $\mathrm{cv}$. Marandu em resposta à adubação fosfatada. Revista Agrarian, v.4, p.335-343, 2011.

Santos, I. P. A. dos; Pinto, J. C.; Siqueira, J. O.; Morais, A. R. de; Santos, C. L. dos. Influência do fósforo, micorriza e nitrogênio no conteúdo de minerais de Brachiaria brizantha e Arachis pintoi consorciados. Revista Brasileira de Zootecnia, v.31, p.605-616, 2002. http://dx.doi.org/10.1590/S1516-35982002000300010

Soares, I.; Lima, S. C.; Crisóstomo, L. A. Crescimento e composição mineral de mudas de gravioleira em resposta a doses de fósforo. Revista Ciência Agronômica, v.38, p.343-349, 2007.

Taiz, L.; Zeiger, E. Fisiologia vegetal. Porto Alegre: Artmed, 2009. $848 \mathrm{p}$.

Valle, C. B.; Euclides, V. P. B.; Valério, J. R.; Macedo, M. C. M.; Fernandes, C. D.; Dias Filho, M. B. Brachiaria brizantha cv. Piatã: Uma forrageira para diversificação de pastagens tropicais. Seed News, v.11, p.28-30, 2007. 